\title{
CONEXÃO TERAPIA COMUNITÁRIA INTEGRATIVA (TCI) E SAÚDE MENTAL
}

\author{
CONNECTION BETWEEN INTEGRATIVE COMMUNITY THERAPY \\ (ICT) AND MENTAL HEALTH
}

\author{
Semírames Cartonilho de Souza Ramos ${ }^{1}$ \\ Ana Lúcia Basilio Carneiro ${ }^{2}$ \\ Mariana Nunes Azevedo de Melo $^{3}$
}

RESUMO: Objetivo: Relatar a experiência com rodas de Terapia Comunitária Integrativa (TCl) no Projeto de Extensão NeuroConexões, da Universidade Federal da Paraíba (UFPB). Método: Neste trabalho foi utilizado a metodologia da contextualização, seguida de exposição das experiências vividas nas rodas de $\mathrm{TCl}$, abertas à comunidade geral e da UFPB. As rodas de $\mathrm{TCl}$ foram realizadas no Laboratório de Práticas Corporais, sala 44, no departamento de Terapia Ocupacional do Centro de Ciências da Saúde (CCS) da UFPB. A terapia foi dividida em cinco momentos, guiados por uma Terapeuta e uma Co-terapeuta, assim direcionados: acolhimento, escolha do tema, contextualização, problematização e encerramento. Resultados: Foram realizadas cinco rodas de TCl em 2019, com um total de 66 participantes, incluindo acadêmicos de Terapia Ocupacional, Fonoaudiologia, Fisioterapia, Ecologia, Direito, Ciência da Computação, Hotelaria, servidores da UFPB, bem como outros participantes da comunidade externa. Os assuntos apresentados durante as 'rodas de $\mathrm{TCl}$ levantavam problemáticas e inquietações, sendo os temas mais recorrentes: ansiedade, medo, dependência emocional, incompreensão no âmbito universitário, culpa por não conseguir administrar as finanças, incongruência, autossabotagem, indecisão, sobrecarga de trabalho, dificuldades de relacionamento e desconforto com o papel do homem na sociedade. Conclusão: A TCl é uma potente ferramenta que oportuniza um espaço de fala e de escuta contribuindo no processo de cuidar da comunidade, sendo uma estratégia de

\footnotetext{
${ }^{1}$ Enfermeira, Dra. em Obstetrícia, Ginecologia e Mastologia, especialista em Enfermagem Obstétrica, Enfermagem em UTI Neonatal e Enfermagem em Urgência e Emergência. Professora na área da saúde da mulher e do neonato. Capacitada em Terapia Comunitária Integrativa. semiramesramosmoga@gmail.com;

2 Dentista, Dra. em Biotecnologia, mestre e especialista em Psicobiologia, especialista em Anatomia Patológica e Acupuntura. Professora de Neuroanatomia da Universidade Federal da Paraíba (UFPB), Cidade Universitária - João Pessoa - PB - Brasil. analucarneiro@gmail.com.

${ }^{3}$ Acadêmica de Fonoaudiologia da UFPB. mariananadm@gmail.com.
} 
promoção da saúde e da qualidade de vida contribuindo para o alívio das cargas emocionais, na construção de redes e parcerias e reorganização da vida.

Descritores: Acolhimento. Resiliencia. Qualidade de Vida.

ABSTRACT: Objective: To report the experience with Integrative Community Therapy (ICT) circles in the NeuroConexões Extension Project, of the Federal University of Paraíba (UFPB). Method: In this work the contextualization methodology was used, followed by the sharing of the experiences encountered in the ICT circles, open to the general community and to the UFPB. The ICT circles were conducted in room 44, at the Body Practices Laboratory, in the Occupational Therapy Department of the Health Sciences Center of the UFPB. The therapy was divided into five moments, guided by a Therapist and a Co-therapist, these moments were: reception, choice of theme, contextualization, problematization and closure. Results: Five ICT circles were conducted in 2019, with a total of 66 participants, including Occupational Therapy, Speech Therapy, Physiotherapy, Ecology, Law, Computer Sciences and Hotel Business scholars, UFPB employees and external community. The subjects presented during the ICT circles raised problems and concerns, and the most recurrent themes were: anxiety, fear, emotional dependence, incomprehension in the university sphere, guilt for not being able to manage finances, incongruence, self-sabotage, indecision, work overload, relationship difficulties and discomfort regarding the role of men in society. Conclusion: The ICT is a powerful tool which enables a speaking and listening space contributing to the process of caring for the community, and is a strategy to promote health and quality of life, contributing to the relief of emotional loads, in the construction of networks and partnerships and reorganization of life.

Descriptors: Reception. Resilience. Quality of Life. 


\section{INTRODUÇÃO}

A Terapia Comunitária Integrativa ( $\mathrm{TCl}$ ) é um dos instrumentos que compõem as Práticas Integrativas e Complementares em Saúde (PICS) do Ministério da Saúde (MS) como estratégia terapêutica grupal. O MS definiu a $\mathrm{TCl}$ como uma "Prática terapêutica coletiva que envolve os membros da comunidade numa atividade de construção de redes sociais solidárias para promoção da vida e mobilização dos recursos e competências dos indivíduos, famílias e comunidades" (BRASIL, 2018).

A TCl é uma tecnologia de cuidado criada no nordeste do Brasil em 1987 pelo médico (etno)psiquiatra, filósofo, teólogo, antropólogo e professor cearense Dr. Adalberto de Paula Barreto. Surgiu como uma ferramenta para fortalecer as relações humanas, construir redes de apoio social, resgatar a autoestima e o poder de resiliência (BARRETO, 2019).

Utiliza-se a roda de terapia como espaço plural de acolhimento, a fim de gerar um momento de escuta, partilha de problemáticas causadoras de sofrimento, troca de experiências de vida, histórias de superação e a formação de novos vínculos. Busca, assim, de forma horizontal e circular, a inclusão social e o cuidado à saúde mental através das potencialidades dos participantes e das práticas e crenças culturais. Nessa perspectiva, a TCl é uma ferramenta de prevenção e promoção da saúde mental comunitária (BARRETO, 2019; MARTINI, 2017a e b). Mourão et al., (2016) em sua revisão integrativa concluiu que:

As evidências mostram que a $\mathrm{TC}$ vem se inserindo gradativamente na prática dos profissionais da saúde, em especial entre os profissionais da saúde mental, e, segundo os artigos científicos analisados, as terapias proporcionaram aos seus participantes a melhora da autoestima, maior segurança na tomada de decisões, reintegração social e fortalecimento dos vínculos familiares, de amizade e espirituais. 
A TCl enquanto intervenção tem objetivo de acolher e cuidar para reforçar a autoestima, estimular a autonomia e a autotransformação e resgatar competências individuais e coletivas (BARRETO, 2019; MARTINI, 2017a e b).

O símbolo da TCl é uma teia de aranha, para Barreto (2019) "a aranha sem a teia é como uma comunidade sem vínculos", assim o símbolo nos remete a formação de vínculos interpessoais e sociais em conexão aos valores culturais. Um símbolo contém em si diferentes funções sígnicas e mantém relações conscientes e inconscientes. Nessa perspectiva, a forma da teia de aranha lembra ainda uma forma circular, labiríntica, tema comum na representação do inconsciente e considerado ainda símbolo da psique (JUNG et al., 2008).

A TCl tem como suporte teórico o pensamento sistêmico, a teoria da comunicação, a antropologia cultural, a resiliência e a Pedagogia Freiriana (BARRETO, 2019). Para Braz et al. (2017) a TCl é um conhecimento pluridimensional que integra saberes e mantém profunda relação prática com a Gestalt-Terapia.

O projeto de extensão NeuroConexões: saúde, bem-estar e práticas integrativas para você aprender, ensinar e cuidar, acredita em um cuidado holístico e na saúde mental além dos psicofármacos. Este estudo objetivou relatar a experiência com rodas de $\mathrm{TCl}$ no Projeto de extensão NeuroConexões, da Universidade Federal da Paraíba (UFPB).

\section{MÉTODO}

Neste trabalho foi utilizada a metodologia da contextualização, seguida de exposição das experiências vividas nas rodas de $\mathrm{TCl}$, abertas à comunidade geral e da UFPB. As rodas de TCI foram realizadas em sala 44, no Laboratório de Práticas Corporais, no departamento de Terapia Ocupacional do Centro de Ciências da Saúde (CCS) da UFPB. Este estudo foi aprovado pelo Comitê de Ética em Pesquisa (CEP), CCS/UFPB, parecer número 3.608 .356 e todos os participantes assinaram o 
Termo de Consentimento Livre e Esclarecido (TCLE), autorizando a utilização de imagens e relatos.

A terapia é dividida em cinco momentos guiados por uma Terapeuta e uma Co-terapeuta, são eles: acolhimento, escolha do tema, contextualização, problematização e encerramento. Durante as rodas de terapia a terapeuta escuta com paciência, trabalha o sofrimento, estimula a partilha, interage com igualdade, fala de seus sentimentos e ajuda a descobrir os recursos individuais do grupo. Criatividade e intuição são características importantes na condução das rodas de terapia. Além disso, o terapeuta partilha emoção, "ri com os que riem, chora com os que choram, canta com os que cantam e se cura com a escuta dos outros" (BARRETO, 2019).

Todas as etapas da terapia são de suma importância e devem ser bem conduzidas de forma a proporcionar ambiente de agregação, respeito e confiança. $O$ acolhimento representa a iniciação ao desenvolvimento de sentimento gregário onde começa-se a perceber o privilégio de estar junto a pessoas especiais, contribuindo para um clima de amor, companheirismo e amizade no grupo. Nesse acolhimento são dadas as boas vindas, que podem ser com uma música, um poema. Apresentase a equipe, o que é a TCl e as regras que são o silêncio, falar de si, usando o eu, não dar conselhos, não julgar, não dar sermões, nem discurso, nem análise. As regras garantem a interação com a diversidade cultural da comunidade e suas manifestações, desafia os participantes a conviver, respeitar as diferenças, tolerar a pluralidade, ouvir o outro e se ouvir, sendo a cultura bem vinda e estimulada a sua utilização, podendo estar presente em todas as etapas da TCl. Celebra-se comemorando algum acontecimento e realiza-se uma dinâmica para descontrair, integrar o grupo.

"Quando a boca cala, os órgãos falam, quando a boca fala, os órgãos saram" (BARRETO, 2019). Esse é um provérbio bastante utilizado para iniciar a etapa da escolha do tema, estimulando o grupo a refletir sobre o que the tem feito mal e sobre a necessidade do alívio ou cura. Perguntas como o que te faz chorar lá no seu quarto sozinho? Ou o que tem feito você entristecer ou tem te preocupado? Favorecem a reflexão sobre o tema que está incomodando. 
Após exposição dos temas e escolha do que vai ser o motivo da $\mathrm{TCl}$ mais informações são apresentadas, por quem o sugeriu, para que haja melhor compreensão quanto ao problema e seu contexto. E logo após na etapa da problematização o mote ou pergunta chave é lançado e vai permitir que o restante do grupo reflita e fale das suas emoções, do que os tocou e chamou a atenção, e sobre como fez para resolver ou conviver melhor com a situação. O respeito a regra de não dar conselhos é muito importante nessa etapa tendo em vista que através das falas onde cada participante relata suas experiências pessoais e suas estratégias, o alcance é coletivo pois cada um irá refletir sobre o que ecoa e faz sentido pessoalmente.

Depois de atingir o objetivo da problematização o encerramento foi realizado utilizando rituais de agregação, visando sempre o resgate das características positivas, a coragem, a determinação, o esforço, a confiança, a amizade, a fé. Este momento representa um espaço de emoção, espiritualidade e que induz cada um a perceber, que fazer tudo isso, participar de tudo isso, não é uma obrigação, mas uma satisfação, um conforto e uma esperança.

\section{RESULTADOS}

Foram realizadas cinco rodas de $\mathrm{TCl}$, em 2019, com um total de 66 participantes, incluindo acadêmicos de Terapia Ocupacional, Fonoaudiologia, Fisioterapia (UEPB), Ecologia, Direito, Ciência da Computação, Hotelaria, servidores da UFPB e participantes da comunidade externa.

Para os rituais de acolhimento diversas estratégias foram utilizadas: a música cantada ao violão pelos participantes da própria roda e por tocadores convidados, o que favorecia a integração e companheirismo; sempre muito cuidado com o acolhimento através da ambiência onde o espaço era caprichosamente organizado, enfeitado e aromatizado, com o intuito de promover ambiente agradável e acolhedor; havia o mimo de oferecer água e algumas guloseimas; buscava-se um clima de 
descontração através de dinâmicas animadas, divertidas e inéditas. A regra da cultura foi muito utilizada através da música, provérbios e poesia.

Os temas abordados em roda eram sempre escolhidos democraticamente. Procurando evitar possíveis constrangimentos ou mal estar, a mediadora sempre ressaltou que a votação era no tema e não na pessoa que o sugeriu e que o tema que não foi escolhido poderá ser apresentado em outra oportunidade. Em todas as rodas surgiram mais de três temas. Sempre antes da contextualização a mediadora agradecia a todos que apresentaram temas.

Os assuntos apresentados durante as TCls levantavam problemáticas e inquietações, sendo os temas mais recorrentes: ansiedade, medo, dependência emocional, incompreensão no âmbito universitário, culpa por não conseguir administrar as finanças, incongruência, autossabotagem, indecisão, sobrecarga de trabalho, dificuldades de relacionamento e desconforto com o papel do homem na sociedade.

As rodas seguiram um curso espontâneo, comprometido com o humano, sem rigorosa preocupação com o tempo e favorecendo a fala e escuta de qualidade. Após a situação problema ser escolhida, os mediadores se colocavam à disposição para alguma orientação no final da roda. Seguia-se a etapa da contextualização onde o participante, cujo tema foi eleito, falava mais sobre o seu desconforto e todos da roda tinham oportunidade de fazer perguntas, favorecendo o esclarecimento e contextualização do tema; logo após, o terapeuta lançava o mote clássico e perguntava se alguém já passou por algo semelhante e o que fez para superar. A partir da troca de experiências e dos relatos das estratégias para superação do desconforto, iniciava-se um processo de reflexão coletiva e resiliência no grupo.

Os temas apresentadas nas rodas de $\mathrm{TCl}$ somados à identificação do grupo, a votação e a contextualização refletem o sofrimento psíquico da comunidade acadêmica, provavelmente, associados a percepções negativas da vida acadêmica e seus estressores, às condições socioeconômicas, relacionais e de gênero. Esses fatores observados confirmam os dados da literatura. (GRANER; CERQUEIRA, 2019).

$\mathrm{Na} \mathrm{TCl}$ a palavra é um bálsamo para quem fala e para quem escuta. A fala na roda de $\mathrm{TCl}$ dispensa qualquer tipo de preparo ou habilidade, fala-se na primeira 
pessoa, aqui o eu, a sabedoria pessoal e a experiência de superar tem vez e voz, é oportunidade de partilhar para transformar. Nesse ambiente há uma clara parceria de saberes, popular e acadêmico. Esse processo educativo terapêutico, de mão dupla, envolve falar e escutar, ensinar e aprender, dar e receber de forma circular através do resgate de histórias e competências individuais e coletivas.

Durante o encerramento os participantes se abraçavam em suave balanço, ombro a ombro, pé a pé cantando uma canção "tô balançando na minha vida, tô balançando mas não vou cair" e o terapeuta fazia uma conotação positiva para o protagonista e para os outros que se colocaram: "Você foi muito corajoso e inteligente nas suas estratégias", oportunizou um momento de falas, em que era possível relatar o que cada um levaria da roda. Continuava utilizando a cultura através das canções ou o que surgisse com relação ao momento. Se fosse necessário, seriam realizados encaminhamentos para a rede de serviços e o terapeuta sempre se colocava à disposição do grupo.

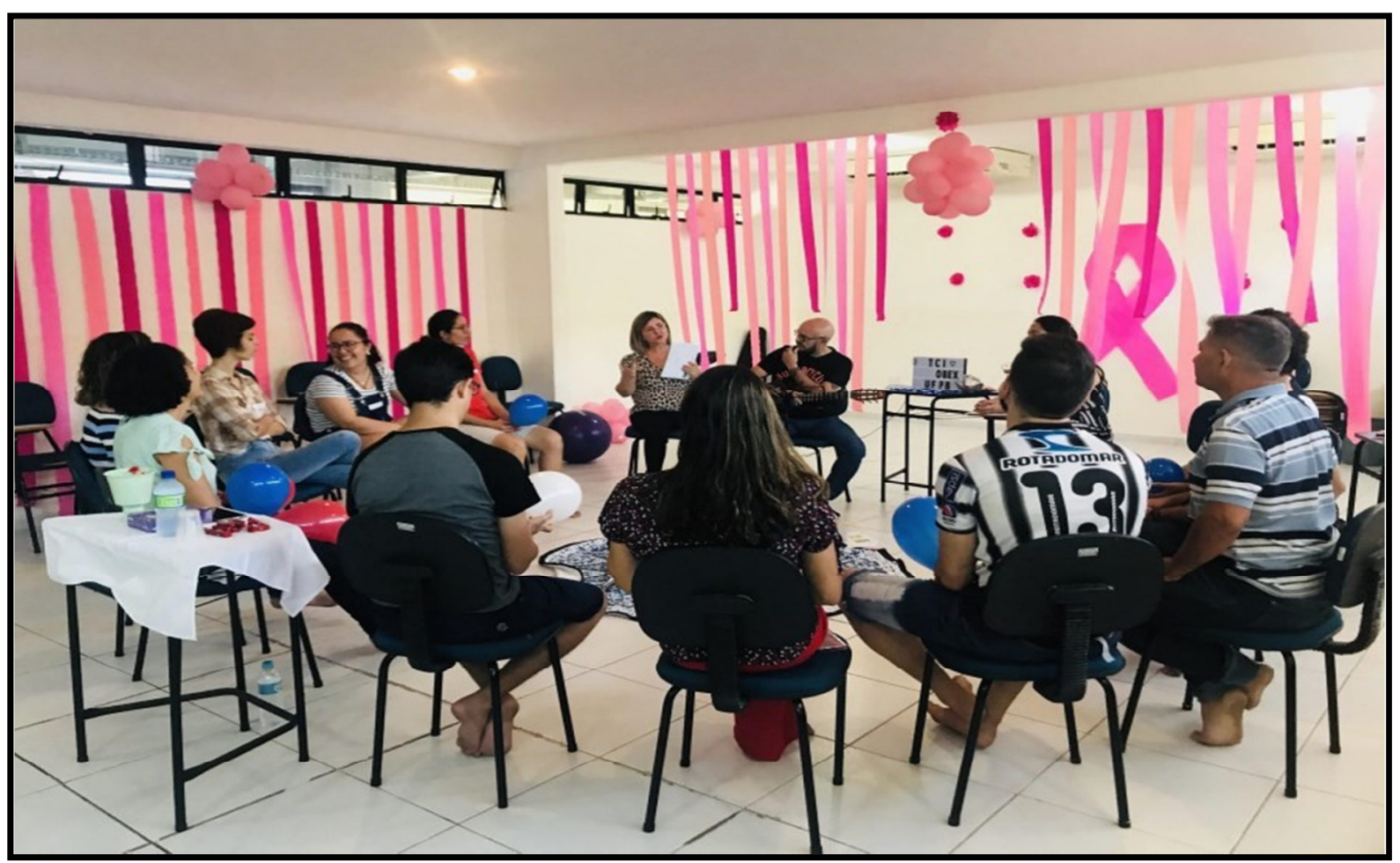

Figura 1. Roda de TCI, sala 44, departamento de Terapia Ocupacional, CCS, UFPB. 
Considerando o perfil do grupo e a utilização das redes sociais descreve-se, a seguir, alguns comentários compartilhados nos stories do instagram pelos participantes após a vivência nas rodas de TCl:

"Sem palavras para essa TCl e para esse projeto...Cada vez com maior certeza que estou no caminho certo e com as pessoas certas";

"Que caminho lindo trilhamos juntos, que experiências transformadoras esse projeto nos proporciona. $+1 \mathrm{TCl}$ incrível para ficar na memória“.

"Foi incrível, intensa e renovadora demais. Só gratidão por tudo e por esse projeto";

"Vocês não tem ideia do quanto mudam vidas!";

"Foi muito importante e maravilhoso";

"Foi lindo demais";

"Muita gratidão por esse projeto";

"Esse projeto só nos proporciona experiências incríveis. Gratidão por fazer parte dele e por espalhar o cuidado e o amor por aí. Decidir fazer parte desse projeto foi uma das melhores escolhas que fiz na vida, sem dúvidas! A vida se torna mais leve porque tenho vocês";

"Foi uma experiência incrível demais";

"Foi um momento maravilhoso";

"Apaixonado pela Terapia Comunitária Integrativa"; 
"Por meio das declarações expressas durante as vivências nas rodas de $\mathrm{TCl}$ torna-se perceptível como a $\mathrm{TCl}$ desabrochou a cosmovisão desses sujeitos ao estimular e conscientizar para a organização do pensar e do agir trazendo assim nitidez para suas vidas".

No ritual de encerramento e agregação quase sempre parecia que o grupo não queria sair dali, tamanha solidariedade e sentimento gregário que surgia nas rodas.

\section{CONCLUSÕES}

A $\mathrm{TCl}$ é uma potente ferramenta que oportuniza um espaço de fala e de escuta, contribuindo no processo de cuidar da comunidade, sendo uma estratégia de promoção da saúde e da qualidade de vida. As rodas de TCl são muito eficientes no sentido de comportar grande número de pessoas em cada encontro, oportunizando espaço de partilha e formação de redes a muitas pessoas ao mesmo tempo.

Um dos grandes desafios da TCl é construir uma rede de cuidados através de uma relação grupal de afeto, baseada no respeito, na valorização e na ressignificação das histórias de vida. É uma estratégia de baixo custo e viável em ambientes simples, o que favoreceu a realização dos encontros. Nas TCl's acima citadas, a cada encontro, os participantes relataram ressignificação, alívio das cargas emocionais, construção de redes e parcerias, reorganização da vida, amadurecimento quanto a valores, e a gratidão ao grupo pela possibilidade de consolidação de vínculos e solidariedade.

Percebemos, com clareza, que a $\mathrm{TCl}$ não é um método absoluto em si mesmo, podendo haver dificuldades dos participantes em se colocar, entendemos que por ser um espaço público, coletivo, é possível que sofrimentos muito pessoais e profundos não sejam relatados, o que pode propiciar manutenção do sofrimento. Mas, ao mesmo tempo, esta metodologia se constitui num importante instrumento de 
reflexão pessoal possível de impulsionar a busca de outros caminhos terapêuticos em busca da cura emocional.

\section{REFERÊNCIAS BIBLIOGRÁFICAS}

BARRETO, A. P. Terapia Comunitària: passo a passo. Fortaleza: Gráfica LCR, 2019.

BRASIL. Glossário Temático: práticas integrativas e complementares em saúde. Brasília, Brasil: Ministério da Saúde. Secretaria-Executiva. Secretaria de Atenção à Saúde, 2018.

BRAZ, J. L. et al. Terapia Comunitária Integrativa e Seu Diálogo com a Gestalt- Terapia. IGT Rede, Rio de Janeiro, v. 14, n. 27, p. 201-217, 2017. Disponível em: $<$ http://pepsic.bvsalud.org/scielo.php?script=sci_arttext\&pid=S1807-

$25262017000200005 \&$ Ing=pt\&nrm=iso > acessos em 02 mar. 2020.

GRANER, K. M.; CERQUEIRA, A. T. A. R. Revisão integrativa: sofrimento psíquico em estudantes universitários e fatores associados. Ciência \& Saúde Coletiva, v. 24, p. 1327-1346, 2019.

JUNG, C. G. O Homem e Seus Símbolos. Trad. Maria Lúcia Pinho. Rio de Janeiro: Nova Fronteira, 2008.

MARTINI, M. G. P. Dinâmicas de Grupos e Jogos Relacionais. Porto Alegre: Caifcom, 2017 .

MARTINI, M.G.P. E quem Cuida de Mim. Porto Alegre: Caifcom Editora, 2017b.

MOURÃO, L. F. et al. Terapia Comunitária como novo recurso da prática do cuidado: revisão integrativa. SANARE-Revista de Políticas Públicas, v. 15, n. 2, 2016. 